\title{
Genetic characterization, antibiogram pattern, and pathogenicity of Clostridium perfringens isolated from broiler chickens with necrotic enteritis
}

\author{
${ }^{1}$ R. D. Eraky and ${ }^{2 *}$ W. A. Abd El-Ghany \\ ${ }^{I}$ Department of Bacteriology, Animal Health Research Institute (Damietta branch), \\ Damietta, Egypt \\ ${ }^{2}$ Department of Poultry Diseases, Faculty of Veterinary Medicine, \\ Cairo University, Giza, Egypt \\ *Corresponding E-mail: wafaa.soliman1974@gmail.com
}

Received June 14, 2021; Accepted October 24, 2021

\begin{abstract}
The aims of this investigation were characterization, demonstration of the antibiogram pattern and detection of the pathogenicity of Clostridium perfringens (C. perfringens) strains isolated from broiler chickens in Damietta governorate, Egypt. A total of 357 samples representing 202 intestinal contents and 155 liver samples from freshly dead broiler chickens were collected from 18 broiler farms. Isolates of $C$. perfringens were identified morphologically, microscopically, and biochemically. Forty-seven $C$. perfringens isolates were recovered, which represented $20.3 \%$ of the intestinal contents and $3.8 \%$ of the liver samples. The toxins and virulence genes of $C$. perfringens were investigated using polymerase chain reaction. All of the toxigenic C. perfringens strains were type A and carried netB, tpeL, cpe, and plc genes. The in vitro antibiogram of $C$. perfringens strains revealed $100 \%$ sensitivity to gentamycin and levofloxacin and $100 \%$ resistance to nalidixic acid and ceftriaxone. The isolated $C$. perfringens strains were highly pathogenic and induced signs and lesions of necrotic enteritis as well as $43.3 \%$ mortalities in 20-day-old chicks. In conclusion, C. perfringens is an important pathogen that affects broiler chickens due to the presence of virulence genes and the pathogenicity in the inoculated birds.
\end{abstract}

Keywords: Antibiotics, C. perfringens, PCR, Poultry, Toxins

\section{INTRODUCTION}

Enteric diseases are very important in the poultry industry as they lead to production losses, mortalities, and risk of contamination of poultry products (Dahiya et al., 2006). Infection with Clostridium perfringens (C. perfringens) is considered one of the most critical enteric problems in chickens and causes necrotic enteritis (NE) (Cooper et al., 2013). The first case of NE in fowl was reported in Australia in 1930 and was fully investigated in England (Parish, 1961). Later, the disease spread rapidly in almost all poultry-producing countries around the world (Finken and Wages, 1997). The disease causes severe economic problems represented by low feed conversion rate, mortalities, and increased treatment costs (Cooper and Songer, 2009). The production losses due to NE outbreaks in the global poultry industry are estimated to be US $\$ 6$ billion annually (Moore, 2016). The main sources of NE infection are litter and contami- 
nated environment (Craven et al., 2003; Profeta et al., 2020), and transmission of infection occurs through ingestion of contaminated food and water. Husbandry practices like diet and litter types influence the incidence and severity of NE in poultry (Henry et al., 1995). Two to six-weekold broiler chickens and 12- to 24-week-old layers are highly susceptible to NE (Lovland et al., 2004). Affected birds with acute NE show severe necrosis and damage of the intestinal mucosa, which lead to high mortalities (Wu et al., 2010) and poor performance in subclinical cases (Skinner et al., 2010).

The causative agent of NE is $C$. perfringens, which is a Gram-positive, anaerobic, and spore-forming bacillus (Timbermont et al., 2011). These bacilli are found naturally in the soil, water, sewage, food, and feces as well as in the intestinal tracts of livestock, poultry, and humans (Li et al., 2016). C. perfringens is considered a normal inhabitant of the birds' intestinal tract as well as a potential pathogen causing NE. Strains of $C$. perfringens are divided into seven extracellular toxin types: A, B, C, D, E, F, and G (Rood et al., 2018; Goossens et al., 2020). However, C. perfringens type A and to a lesser extent type $\mathrm{C}$ have been shown to be the major cause of NE in chickens (Cooper and Songer, 2009). Moreover, alpha ( $\alpha$ ) toxin is primarily responsible for NE in poultry (Keyburn et al., 2010). The virulence of $C$. perfringens is attributed to more than 20 toxins and hydrolytic enzymes (Kiu and Hall, 2018; Gu et al., 2019), while individual strains only produce a subset of these toxins (Van Immerseel et al., 2008). Major extracellular toxins of $C$. perfringens are alpha $(\alpha)(c p a)$, beta $(\beta)(c p b)$, epsilon ( $(\varepsilon)(e t x)$, and iota (1) (iap). However, different strains of $C$. perfringens can also produce other enzymes and toxins, namely, $\beta 2$, theta $(\theta)$ [perfringolysin $O$ $(P F O)]$, kappa $(\kappa)$, delta $(\delta), \mathrm{mu}(\mu)$, sialidase, hyaluronidase, collagenase, neuraminidase, enterotoxin (cpe), necrotic enteritis toxin B-like (netB), and toxin perfringens large (tpeL) (Lukinmaa et al., 2002; Li et al., 2013; Duff et al., 2019; Wei et al., 2020).

All C. perfringens type A strains possess phospholipase $\mathrm{C}$ ( $p l c)$ or cpa gene that produces $\alpha$ toxin in varying amounts (Kumar et al., 2019; Helal et al., 2019). This gene is present on the chromosome close to the origin of replication of all C. perfringens strains (Canard et al., 1989). It was found that net $B$ and tpel toxins play a role in the virulence of some $C$. perfringens strains of avian origin (Rood et al., 2016; Elsharkawy et al., 2020; Thi et al., 2021). Most $C$. perfringens strains that produce a pore-forming toxin (netB) belong to toxin type G (Rood et al., 2018). In addition, tpel, a recently designated novel family member of large clostridial cytotoxins, was detected in some $C$. perfringens type A strains isolated from NE cases (Coursodon et al., 2012; Mwangi et al., 2019). Enterotoxin gene (cpe) coding toxin of $C$. perfringens has been identified by Gao and McClane (2012), and it induces gastroenteritis (Lukinmaa et al., 2002).

NE has become a hurdle affecting broiler production especially after the great restrictions on the application of antibiotics in ration under modern high stalking density (Van Immerseel et al., 2008). Therefore, there is an urgent need to select the drug of choice to control this critical disease.

Therefore, this study aimed to characterize, investigate the antibiogram pattern and determine the pathogenicity of $C$. perfringens strains isolated from broiler chickens in Damietta governorate, Egypt.

\section{MATERIALS AND METHODS}

\section{Sample Collection}

A total of 357 samples were taken from 202 intestines and 155 livers of sacrificed diseased and freshly dead chickens (2-8-week-old) representing 18 commercial broiler chicken farms at different locations in Damietta governorate, Egypt, from December 2019 to June 2020 (Table 1). Clinically suspected cases with NE showed anorexia, depression, reluctance to move, diarrhea, and death. Sacrificed and dead chickens showed dehydration, enteritis, ballooned and friable intestines with hemorrhages, and yellow diphtheritic necrotic membranes on the mucosa 
Table 1. The number of the examined samples distributed in Damietta governorate, Egypt

\begin{tabular}{cccc}
\hline \multirow{2}{*}{ Locality } & \multirow{2}{*}{$\begin{array}{c}\text { Number of } \\
\text { examined farms }\end{array}$} & \multicolumn{2}{c}{ Number of examined samples } \\
\cline { 3 - 4 } & 3 & Intestine & Liver \\
\hline Kafer-Saad & 3 & 18 & 18 \\
Farskour & 4 & 32 & 31 \\
Om El-Reda & 2 & 44 & 40 \\
Kafer El-Batekh & 1 & 19 & 9 \\
Cinania & 2 & 11 & 11 \\
Kafer-ElGhabe & 3 & 35 & 29 \\
Zarka & 18 & 43 & 17 \\
\hline Total & 202 & 155 \\
\hline
\end{tabular}

as well as liver necrosis. The samples were aseptically collected in sterile plastic bags and quickly transported to the laboratory in ice-cooled containers for further microbiological examination.

\section{Conventional Isolation and Identification}

Sample processing was done according to a routine protocol as previously described by Willis (1977). For enrichment, one gram of each of the intestinal contents or liver tissue samples was inoculated into tubes of freshly prepared Robertson cooked meat broth (Oxoid, UK) and incubated for $24 \mathrm{~h}$ at $37^{\circ} \mathrm{C}$ in a Gas-Pak anaerobic jar. Aliquots of $0.1 \mathrm{ml}$ were streaked onto a perfringens agar base containing $400 \mu \mathrm{g} / \mathrm{ml}$ of tryptose sulfite cycloserine (TSC) with egg emulsion (Oxoid, UK) and incubated anaerobically. For the proliferation and detection of the hemolytic characteristics of Clostridium isolates, $5 \%$ de-fibrinated sheep blood agar with neomycin sulphate $(200 \mu \mathrm{g} / \mathrm{ml})$ was prepared. After $24-$ $48 \mathrm{~h}$ incubation at $37^{\circ} \mathrm{C}$, typical black colonies were selected and cultured onto de-fibrinated 5\% sheep blood agar and egg yolk agar plates and incubated anaerobically for $24 \mathrm{~h}$ at $37^{\circ} \mathrm{C}$ (Cruickshank et al., 1975). Typical colonies on blood agar or egg yolk agar were further identified according to the morphological characteristics using Gram staining and different biochemical tests, such as catalase, nitrate reduction, gelatinase, lecithinase, indole, oxidase, urease storm gas production on litmus milk medium, and fermentation of glucose, lactose, fructose, sucrose, and mannitol.

\section{Molecular Detection of the Toxins and Viru- lence Genes}

DNA extraction from suspected samples was performed using the QIAamp DNA Mini Kit (Qiagen, Germany, GmbH) with modifications according to the manufacturer's recommendations. Briefly, $200 \mu 1$ of the sample suspension was incubated with $10 \mu \mathrm{l}$ of proteinase $\mathrm{K}$ and $200 \mu \mathrm{l}$ of lysis buffer at $56^{\circ} \mathrm{C}$ for $10 \mathrm{~min}$. After incubation, $200 \mu 1$ of $100 \%$ ethanol was added to the lysate. The sample was then washed and centrifuged following the manufacturer's recommendations. Nucleic acid was eluted with $100 \mu 1$ of elution buffer provided in the kit. Primers provided by Metabion (Germany) are listed in Table (2). Multiplex polymerase chain reaction (PCR) was used for the detection of $\alpha, \beta, \varepsilon$, and $\imath$ toxins. Primers were utilized in a $50 \mu 1$ reaction containing $25 \mu 1$ of Emerald Amp Max PCR Master Mix (Takara, Japan), $1 \mu 1$ of each primer of 20 pmol concentration, $11 \mu \mathrm{l}$ of water, and $6 \mu 1$ of DNA template. For uniplex PCR, primers were utilized in a $25 \mu 1$ reaction containing $12.5 \mu 1$ of Emerald Amp Max PCR Master Mix (Takara, Japan), $1 \mu 1$ of each primer of 20 pmol concentration, $5.5 \mu 1$ of water, and $5 \mu 1$ of DNA template. All the reactions were performed in an Applied Biosystems 2720 thermal cycler.

The products of PCR were separated by electrophoresis on $1.5 \%$ agarose gel (Applichem, Germany, GmbH) in 1x TBE buffer at room temperature using gradients of $5 \mathrm{~V} / \mathrm{cm}$. For gel analy- 
Table 2. Primers sequences, target genes, amplicon sizes and cycling conditions for C. perfringens.

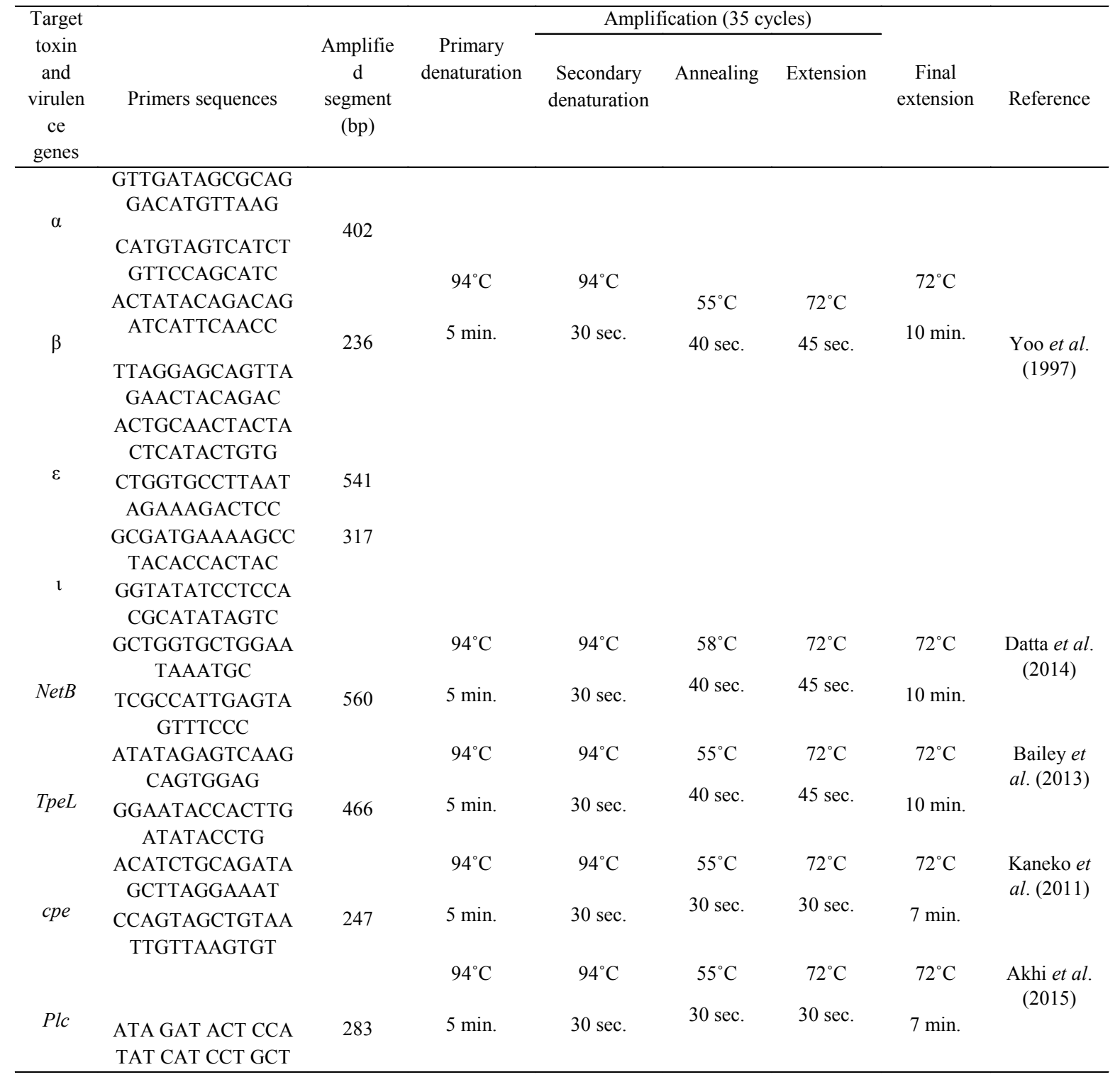

sis, $40 \mu \mathrm{l}$ of the multiplex PCR products and 15 $\mu 1$ of the uniplex PCR products were loaded in each gel slot. A gel pilot 100 bp ladder (Qiagen, Gmbh, Germany) and gene ruler 100 bp ladder (Fermentas, Thermo, Germany) were used to determine the fragment sizes. The gel was photographed using a gel documentation system (Alpha Innotech, Biometra), and the data was analyzed through computer software.

\section{The Antibiogram Pattern}

The antimicrobial susceptibility testing of C. perfringens strains was done using the disc diffusion method developed by the National
Committee for Clinical Laboratory Standards (NCCLS, 2007). The used chemotherapeutic agents discs (Oxoid) and the inhibition zones (susceptible, intermediate susceptibility, and resistant) are shown in Table (3). All $C$. perfringens strains were cultivated in cooked meat broth for $24 \mathrm{~h}$, and then the culture broth was suspended into $0.85 \% \mathrm{NaCl}$ to obtain an optical density equal to MacFarland 0.5 standards. After that, the strains were inoculated in $5 \%$ defibrinated sheep blood agar for 10 minutes and the antibiotic discs were dispersed in the agar plates. The plates were incubated anaerobically at $37^{\circ} \mathrm{C}$ overnight, and the inhibition zones were 


\begin{tabular}{lcccc}
\hline & & \multicolumn{3}{c}{$\begin{array}{c}\text { Interpretation } \\
\text { (Diameter of the zone/ mm) }\end{array}$} \\
\cline { 3 - 5 } \multicolumn{1}{c}{ Antibiotic disc (Code) } & Disc content/ $\mu \mathrm{g}$ & Susceptible $\geq$ & $\begin{array}{c}\text { Intermediate } \\
\text { susceptibility }\end{array}$ & Resistant $\leq$ \\
\hline Amoxycillin/Clavulanic acid (AMC) & $20 / 10$ & 18 & $14-17$ & 13 \\
Neomycin (NE) & 10 & 17 & - & 16 \\
Doxycycline (Do) & 30 & 16 & $13-15$ & 12 \\
Erythromycin (E) & 15 & 21 & $16-20$ & 15 \\
Nalidixic acid (NA) & 30 & 19 & $14-18$ & 13 \\
Penicillin (P) & 10 & 22 & - & 23 \\
Ciprofloxacin (CIP) & 5 & 21 & $16-20$ & 15 \\
Gentamycin (CN) & 10 & 15 & $13-14$ & 12 \\
Levofloxacin (LEV) & 5 & 17 & $14-16$ & 13 \\
Ceftriaxone (CES) & 30 & 28 & $24-27$ & 23 \\
\hline
\end{tabular}

measured as recommended by the manufacturer.

\section{The Pathogenicity Test in Broiler Chickens}

The experiment was done according to the National Regulations on Animal Welfare and Institutional Animal Ethical Committee (IAEC). A total of 105 day-old Cobb chicks were obtained from local hatcheries, and five birds were subjected on arrival to bacteriological examination to confirm the absence of $C$. perfringens. The chicks were reared on thoroughly cleaned and disinfected semi-closed houses and vaccinated using the standard protocol for vaccination. Feed and water were given ad libitum. The ration was supplemented with $12 \%$ wheat to enhance the experimental induction of infection. The chicks were divided into two equal groups, each containing 50 birds. Group (1) was the negative control non-challenged group and was inoculated with sterile phosphate buffered saline. Each bird in group (2) was orally inoculated with a field mixture of Eimeria oocysts in a dose of $1 \times 10^{3}$ sporulated oocysts $/ 0.1 \mathrm{ml}$ of oocysts mixture at the age of 10 days. However, at the age of 20 days, each chick in group (2) was challenged orally with $1 \mathrm{ml}$ of $24 \mathrm{hr}$ broth culture containing $1.7 \times 10^{8}$ viable cells of the toxigenic strain of $C$. perfringens type $\mathrm{A}$ for four successive days (Timbermont et al., 2009). All chicken groups were kept under observation for two weeks postchallenge (PC) to monitor the clinical picture.

\section{RESULTS AND DISCUSSION}

C. perfringens is a widely distributed bacterium in the environment and is mostly found in the intestinal tracts of humans and domestic animals (Kiu and Hall, 2018). The organism is a major enteric pathogen that can lead to both clinical (Long and Truscott, 1976) and subclinical diseases (Lovland and Kaldhusdal, 2001). The pathogen is responsible for causing NE in poul-

Table 4. The incidence rate and the type of $C$. perfringens in Damietta governorate, Egypt

\begin{tabular}{cccccccc}
\hline \multirow{2}{*}{$\begin{array}{c}\text { Age of } \\
\text { chicken/Week }\end{array}$} & $\begin{array}{c}\text { No. of } \\
\text { samples }\end{array}$ & $\begin{array}{c}\text { No. of } \\
\text { positive }\end{array}$ & $\begin{array}{c}\% \\
\text { positive }\end{array}$ & $\begin{array}{c}\text { No. of } \\
\text { samples }\end{array}$ & $\begin{array}{c}\text { No. of } \\
\text { positive }\end{array}$ & $\begin{array}{c}\% \\
\text { positive }\end{array}$ & $\begin{array}{c}\text { No. of } \\
\text { examined } \\
\text { farms }\end{array}$ \\
\hline $1-2$ & 62 & 2 & 3.2 & 47 & 0 & 0 & 5 \\
$2-3$ & 56 & 15 & 26.8 & 48 & 3 & 6.3 & 10 \\
$3-4$ & 45 & 13 & 28.9 & 39 & 2 & 5.1 & 12 \\
$4-8$ & 39 & 11 & 28.9 & 21 & 1 & 4.8 & 8 \\
Total & 202 & 41 & 20.3 & 155 & 6 & 3.8 & 18 \\
\hline
\end{tabular}


try, especially $C$. perfringens type A, which is the most frequently isolated clostridial type (Opengart, 2008).

Based on the cultural, morphological, and biochemical characteristics of the isolates, $20.3 \%$ and $3.8 \%$ C. perfringens isolates were recovered from 202 intestine and 155 liver samples, respectively, from freshly dead broiler chickens in Damietta governorate (Table 4). Morphologically, C. perfringens isolates grew anaerobically and produced double zones of hemolysis (an inner zone of complete hemolysis and an outer zone of discoloration and incomplete hemolysis) on $5 \%$ sheep blood agar with neomycin sulfate (Figure 1). However, C. perfringens isolates on TSC showed black colonies due to the reduction of sulfite to sulfide, which in turn reacts with iron and forms a black iron sulfide precipitate (Figure 2). A zone of opalescence appeared around the $C$. perfringens colonies on egg yolk agar plates. Microscopically, C. perfringens isolates revealed Gram-positive, non-motile, and spore-forming large-sized bacilli. Biochemically, all $C$. perfringens isolates were positive for nitrate reduction and lecithinase activity (Figure 3 ), but they were negative for catalase, indole production, and oxidase. The isolates produced typical stormy fermentation reaction in litmus milk medium.

Manfreda et al. (2006) isolated $C$. perfringens from broiler farms with a rate over $90 \%$ and found $C$. perfringens in 87 out of 149 samples $(58.40 \%)$. However, the lowest frequency of isolated $C$. perfringens was reported by Kalender and Ertas (2005) who showed that only $5 \%$ of the intestinal contents were positive for $C$. perfringens. In Egypt, Hussein and Mustfa (1999) demonstrated 30 isolates of $C$. perfringens out of 60 intestinal samples $(50 \%)$ in 4-6-week-old broiler chickens in Assiut governorate, while Ebtehal (2000) found that out of 470 broiler chicken samples, 231 (71.9\%) strains of $C$. perfringens could be isolated in Assiut and El-Minia governorates. This high incidence was not surprising if the spread of the microorganisms in the environment, diet, water, litter, and slaughtering houses was considered. Other Egyp-

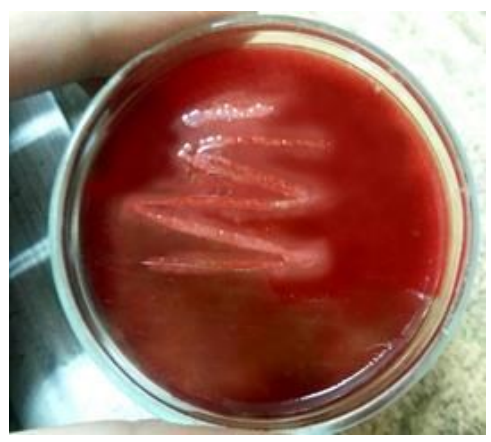

Figure 1. Colonies of $C$. perfringens on 5\% sheep blood agar with neomycin sulfate showing double zones of $\beta$ hemolysis (Inner zone of complete hemolysis and outer zone partial hemolysis).

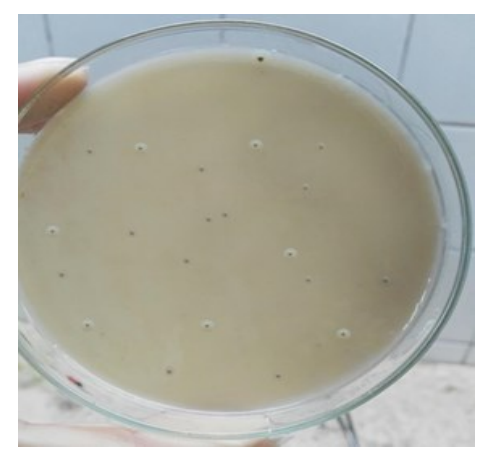

Figure 2. Colonies of $C$. perfringens on tryptose sulfite cycloserin (TSC) showing black colonies.

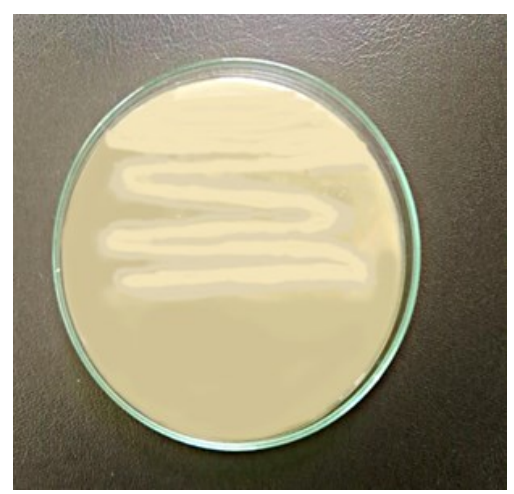

Figure 3. Lecithinase activity of $C$. perfringens on egg yolk agar (lecithinase: $\alpha$ toxin phospholipase hydrolyzes phospholipids in egg yolk agar around streaks).

tian studies reported isolation of $C$. perfringens from the intestines of both apparently healthy and diseased broiler chickens with high rates of $42.0 \%$ and $91.3 \%$, respectively (El-Refaey et al., 1999); $30 \%$ and $75 \%$, respectively (Rasha, 2009); and $35.4 \%$ and $100 \%$, respectively (Osman et al., 2012). Moreover, C. perfringens 


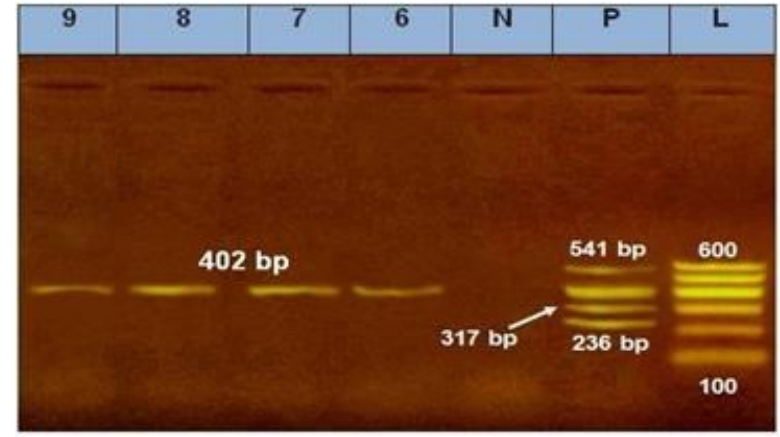

Figure 4. PCR amplification using Clostridium genus -specific primers for toxins $(\alpha, \beta, \varepsilon$ and $\iota), \mathrm{P}=$ Positive control, $\mathrm{L}=$ Ladder, Lines 6-9 $=C$. perfringens type A strains, $\mathrm{N}=$ Negative control.

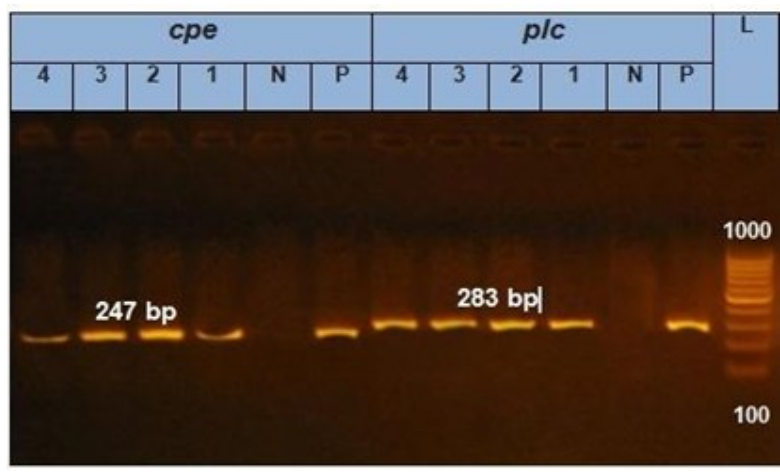

Figure 5. PCR amplification using $C$. perfringens genus-specific primers (cpe and plc genes), $\mathrm{P}=$ Positive control, $\mathrm{L}=$ Ladder, lines $1-4=c p e$ and plc genes of $C$. perfringens, $\mathrm{N}=$ Negative control.

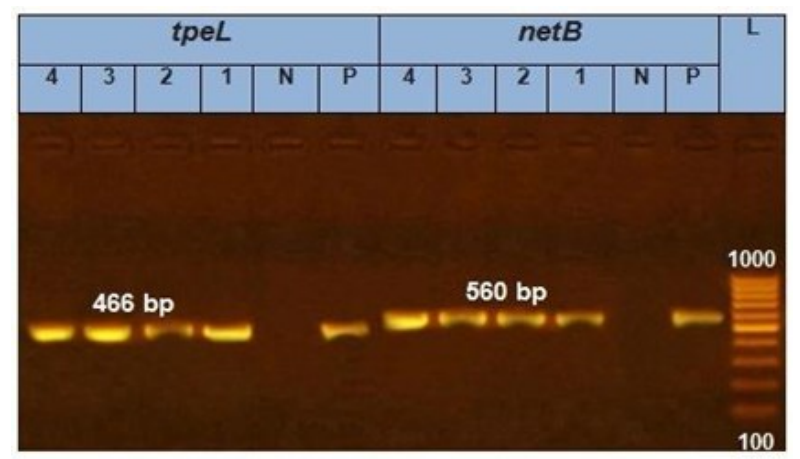

Figure 6. PCR amplification using $C$. perfringens genus-specific primers (tpeL and net $B$ genes), $\mathrm{P}=$ Positive control, $\mathrm{L}=$ Ladder, lines $1-4=$ tpe $L$ and net $B$ genes genes of $C$. perfringens, $\mathrm{N}=$ Negative control.

was isolated from the intestines of chickens with NE with incidence rates of $47.70 \%$ (El-Rash, 2012) and 60\% (Eman et al., 2013). Out of 120 intestine and liver samples taken from diseased broiler chickens, EI-Jakee et al. (2013) isolated $90(75 \%)$ C. perfringens with an incidence rate of $53.8 \%$

Multiplex PCR showed that C. perfringens strains belonged to type A as they contained the cpa gene (402 bp) that coded for $\alpha$ toxin and the $c p b$ (236 bp), etx (541 bp), and iA (317 bp) genes that coded for $\beta, \varepsilon$, and 1 . toxins, respectively (Figure 4). Molecular detection of the virulence genes of $C$. perfringens type A strains showed the presence of the netB, tpeL, cpe, and plc genes in all isolated strains (Figures 5 and 6). The PCRbased detection of $\alpha$ toxin is essential for the typical identification of $\alpha$ toxigenic $C$. perfringens strains (Baums et al., 2004). Several Clostridia enteric diseases occur in poultry, but probably the most common and severe one is NE, caused by $C$. perfringens type A (Moore, 2015). In Sweden, Engstrom et al. (2003) demonstrated that all C. perfringens strains were classified as type A without enterotoxin genes. Furthermore, in Finland, Heikinheimo and Korkeala (2005) showed that 118 poultry isolates of $C$. perfringens were classified as type A strains using multiplex PCR. In a Belgian study, five out of 63 C. perfringens isolates were $\beta 2$ toxin-positive, and the authors indicated that this type of toxin is not an essential virulence factor in the development of $\mathrm{NE}$ in poultry (Gholamiandekhordi et al., 2006).

It is well known that $C$. perfringens type A induces intestinal mucosal damage in chickens (Moore, 2015). The $\alpha$ toxin producing $C$. perfringens is phospholipase $\mathrm{C}$ sphingomyelinase that hydrolyzes lecithin into phosphorylcholine and diglyceride and as a consequence induces the production of inflammatory mediators causing blood vessel contraction, platelet aggregation, myocardial dysfunction, and finally acute death (Matsuda et al., 2019).

Detection of $C$. perfringens toxin types and subtypes is critical for a better understanding of the epidemiology of $C$. perfringens infection and may be helpful in the implementation of effective preventive measures (Fancher et al., 2021). In this study, the presence of eight toxin genes ( $c p a$, $c p b$, etx, iA, netB, tpeL, plc, and cpe) of $C$. perfringens type $\mathrm{A}$ isolates has been investigated. 


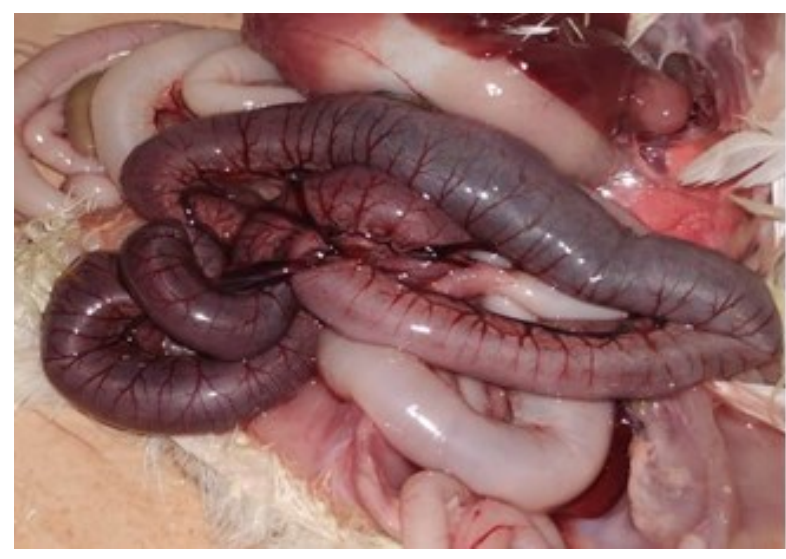

A

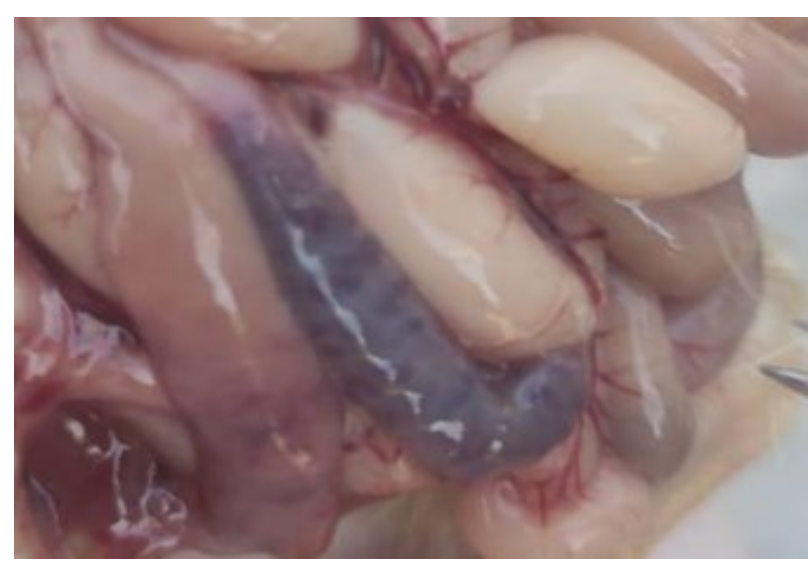

B

Figure 7. A: The intestine is filled with blood (hemorrhagic enteritis) and distended with gases. $\mathrm{B}$ : The caecum is filled with blood (hemorrhagic typhlitis).

The results revealed the presence of netB, tpeL, plc, and cpe genes. This result confirms high production of toxins that lead to the destruction of the intestinal mucosa and consequently the development of NE (Mwangi et al., 2019). Similar findings were reported by Ebtehal (2000) who indicated the role of toxigenic $C$. perfringens in the production of toxins that lead to NE in poultry.

In addition, $C$. perfringens strains possess other common virulence genes (net $B)$ producing $\beta$ toxin (Yang et al., 2018). Since the discovery of this new virulence factor, the presence of the $n e t B$ gene in $C$. perfringens strains has been investigated in different regions of the world. The results indicated the existence of this gene in $C$. perfringens type A strains. Johansson et al. (2010) reported that more than $90 \%$ of all isolates from cases of $\mathrm{NE}$ carried the netB gene. Through the examination of 36 isolates of $C$. perfringens, $19(52.8 \%)$ isolates showed presence of the netB gene (Tolooe et al., 2011). A previous study of Miwa et al. (1998) demonstrated that strains of $C$. perfringens that were netBnegative failed to cause disease in an experimental model, whereas all net $B$-positive strains produced typical lesions of NE. In addition, it has been found that $n e t B$, a pore-forming toxin, plays a role in the pathogenesis of NE in poultry as a strongly necrotizing and lethal toxin (Keyburn et al., 2010; Wade et al., 2020). Native and recombinant net $B$ were cytotoxic for chicken hepatocytes. The net $B$ gene is mostly found in outbreaks of NE but is relatively uncommon in healthy birds (Tolooe et al., 2011). However, several studies demonstrated the absence of the $n e t B$ gene in $C$. perfringens isolates (Datta et al., 2014; Li et al., 2018; Zhang et al., 2019).

Furthermore, all $C$. perfringens type A strains of avian origin possess phospholipase $\mathrm{C}$ (plc) or the cpa gene that produces $\alpha$ toxin (Abildgaard et al., 2009). This gene has also been discovered in strains of human origin (Matsuda et al., 2019). Moreover, Kimy et al. (2017) classified C. perfringens as a toxin type A based on the presence of the $\alpha$ toxin gene $(p l c)$.

Isolates of $C$. perfringens that have $\alpha$ toxins as well as enterotoxin (cpe) are regarded as type F. Enterotoxin (cpe) is produced by about $1 \%$ $5 \%$ of $C$. perfringens type A. This toxin is a single polypeptide chain of about $35 \mathrm{KDa}$ and, unlike other toxins, is released upon lysis of the mother cell in the sporulation stage (Abildgaard et al., 2010). Previous studies showed that there is a relationship between $C$. perfringens type A isolates that carry the cpe gene and foodborne infection (Miyamoto et al., 2012) as well as nonfoodborne gastrointestinal diseases (Azimirad et 


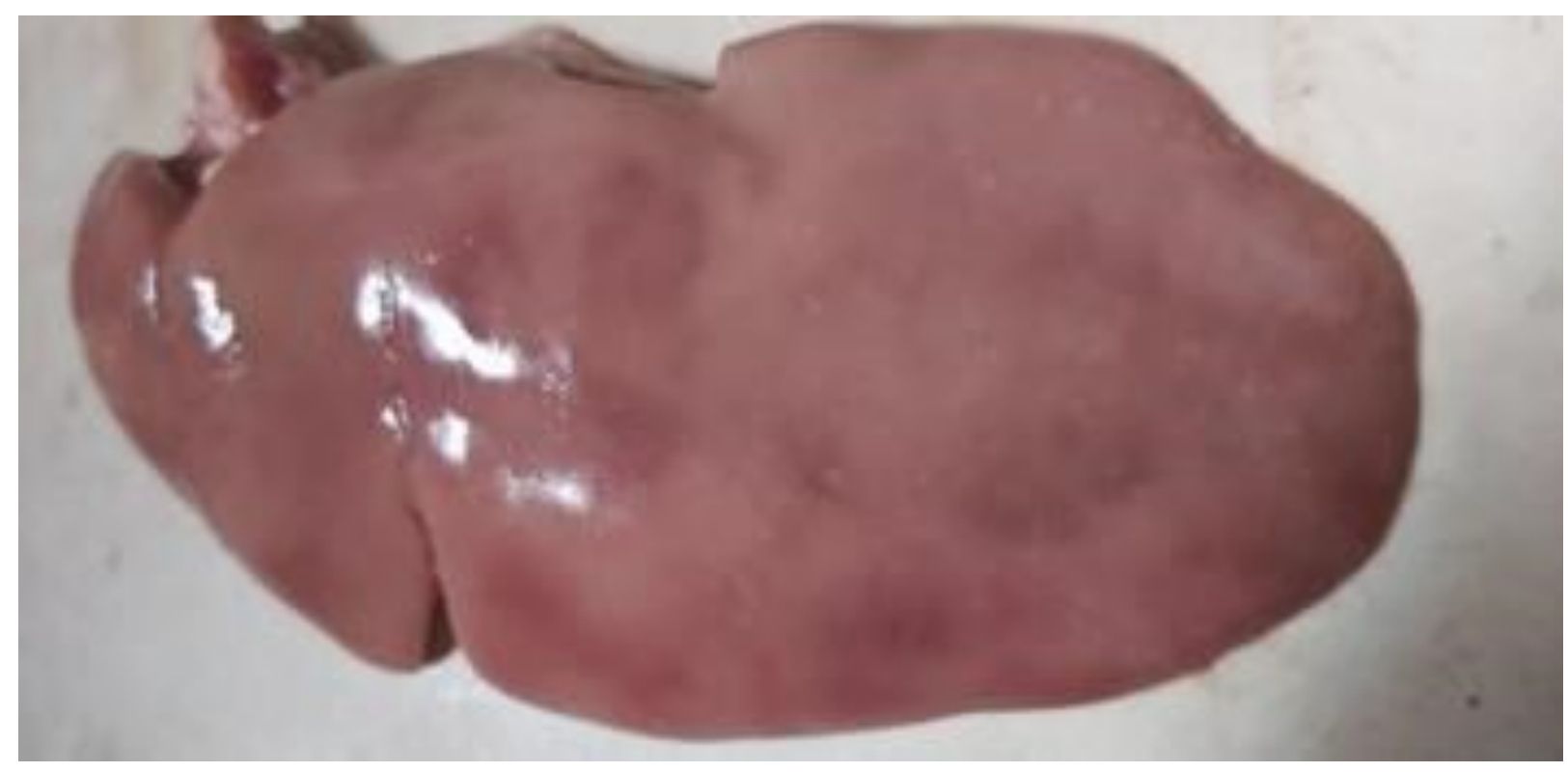

Figure 8. Enlarged and pale liver with necrotic foci.

al., 2019). The findings of this study showed that C. perfringens isolates carry the cpe gene which is similar to the findings of other studies (Asaoka et al., 2004). The authors suggested that cpe plays a role in intestinal necrosis with minor intestinal damage, allowing the multiplication of C. perfringens and consequently development of the disease.

Periodic

evaluation

of

C. perfringens antimicrobial susceptibility testing is important to avoid the losses resulting from this infection (Finken and Wages, 1997). In $47 C$. perfringens strains, the in vitro sensitivity test revealed high susceptibility to levofloxacin and gentamycin $(100 \%)$ as well as ciprofloxacin $(85.1 \%)$. Low degree of susceptibility to doxycycline and erythromycin (25.5\%), in addition to neomycin (23.4\%), was reported. Resistance to penicillin, nalidixic acid, and ceftriaxone was $100 \%$, while resistance to amoxycillin/clavulanic acid was $72.3 \%$ (Table 5). Nearly similar antibiotic sensitive patterns were observed by Mehtaz et al. (2013) who found that C. perfringens isolates were sensitive to some fluoroquinolones, such as ciprofloxacin and ofloxacin. However, these results are inconsistent with those reported by Hussein and Mostfa (1999) who stated that neomycin was highly effective but enrofloxacin was not effective against $C$. perfringens. Algammal and Elfeil (2015) reported 100\% resistance of $C$. perfringens to neomycin, which is commonly used as an antimicrobial drug to treat bacterial enteritis in poultry. In this study, $C$. perfringens isolates showed resistance to nalidixic acid and amoxicillin, similar to the results reported by another study (Camacho et al., 2008). Nevertheless, another study demonstrated a high level of sensitivity to penicillin (Algammal and Elfeil, 2015).

Clinical signs observed among $C$. perfringens-challenged chicks in the challenged group were depression, ruffled feathers, decreased appetite, and diarrhea. Mortalities were observed at $48 \mathrm{hr} \mathrm{PC}$ at a rate of $43.3 \%$. No clinical signs or mortalities were observed in control birds that were inoculated with phosphate buffered saline. The intestines of dead and sacrificed chickens at the end of the observation period were filled with blood (hemorrhagic enteritis) and distended with gases (Figure $7 \mathrm{~A}$ ), and the caecum was filled with blood (hemorrhagic typhlitis) (Figure 7 B). Enlargement, paleness, and necrosis of the liver were also observed (Figure 8). The pathogenesis of $C$. perfringens infection 
involves the colonization of the tissue's host, acquisition of nutrients to allow more multiplication, dodging of the immune system of the host, and finally transmission of toxins with tissue damage (Prescott et al., 2016). The presence of some risk factors associated with $C$. perfringens challenge enhances the development of NE clinical infection. Some predisposing factors, such as Eimeria species and the use of wheat and barley, are important for the induction of NE (Kocher, 2003). Moreover, C. perfringens infection was significantly higher in the presence of stress factors, such as worm infestation or coccidiosis (Mateos et al., 2002). It has been found that $E i$ meria species colonize the bird's intestinal tract, causing damage and releasing plasma proteins which is the minimal requirements for growth of C. perfringens include more than 11 amino acids, besides many growth factors and vitamins (Hofacre et al., 2003). Moreover, Lovland et al. (2004) reported that $C$. perfringens type A causes mucosal damage in the intestines of chickens. Regarding the pathogenicity test in broiler chicks using $C$. perfringens strains, the results revealed general signs with variable degrees of diarrhea, mortalities (43.3\%), and intestinal and liver lesions. Similar observations were reported in previous studies (Freedman et al., 2015; Thi et al., 2021). Lovland and Kaldhusdal (2001) found that NE can present as an acute clinical disease characterized by sudden high mortality rates that can reach $50 \%$ in flocks. Moreover, Ebtehal (2000) found that $C$. perfringens given orally to chicks caused $80 \%$ mortality. Similar intestinal lesions were also reported in previous studies (Park et al., 2015; To et al., 2017; Abdul-Aziz and Barnes, 2018). They mentioned that infected chickens with NE showed intestinal lesions ranging from thin and friable walls to frank hemorrhagic enteritis along with gas distension. In addition, necrotic lesions present on the liver of chickens after $C$. perfringens challenge were the same as the lesions reported by Lovland and Kaldhusdal (2001), Sasaki et al. (2003), and Thi et al. (2021).

\section{CONCLUSION}

Continuous and periodical surveillance studies should be conducted to alleviate the severe economic losses caused by $C$. perfringens infection in broiler chicken flocks. Detection of the sensitivity of the bacterium to different antibiotics is a must before developing successful control and treatment strategies. Future studies on the preparation of bacterin to prevent such infection are needed.

\section{REFERENCE}

Abdul-Aziz, T and H.J. Barnes. 2018. Necrotic enteritis. In Gross Pathology of Avian Diseases: Text and Atlas (pp.50-52). Madison, WI: Omnipress.

Abildgaard, L., T.E. Sondergaard and R.M. Engberg. 2010. In vitro production of necrotic enteritis toxin $\mathrm{B}, \mathrm{NetB}$, by netB positive and netB-negative Clostridium perfringens originating from healthy and diseased broiler chickens. Vet. Microbiol. 144:231-235. https://doi.org/10.1016/ j.vetmic.2009.12.036

Abildgaard, L., R.M. Engberg, K. Pedersen, A. Schramm and O. Hojberg. 2009. Sequence variation in the alpha-toxin encoding plc gene of Clostridium perfringens strains isolated from diseased and healthy chickens. Vet. Microbiol. 136:293-299. https://doi.org/10.1016/ j.vetmic.2008.11.001

Akhi, M.T., S.B. Asl, T. Pirzadeh, B. Naghili, F. Yeganeh, Y. Memar and Y. Mohammadzadeh. 2015. Antibiotic sensitivity of Clostridium perfringens isolated from faeces in $\mathrm{Ta}-$ briz, Iran. Jundishapur J. Microbiol. 8 (7):e20863. jim.20863v2

Algammal, A.M. and W.M. Elfeil. 2015. PCR based detection of Alpha toxin gene in Clostridium perfringens strains isolated from diseased broiler chickens. Benha Vet. Med. J. 229(2):333-338. https:// dx.doi.org/10.21608/bvmj.2015.31744

Asaoka, Y., T. Yanai and H. Hirayama. 2004. 
Fatal necrotic enteritis associated with Clostridium perfringens in wild crows (Corvus macrorhynchos). Avian Pathol. 33(1):1924. https:// doi.org/10.1080/03079450310001636228

Azimirad, M., F. Gholami, A. Yadegar, D.R. Knight, S. Shamloei, H.A. Aghdaei and M.R. Zali. 2019. Prevalence and characterization of Clostridium perfringens toxinotypes among patients with antibioticassociated diarrhea in Iran. Sci. Rep. 9: 7792. https://doi.org/10.1038/s41598-019$\underline{44281-5}$

Bailey, M.A., K.S. Macklin and J.T. Krehling. 2013. Use of a multiplex PCR for the detection of toxin-encoding genes netB and tpeL in strains of Clostridium perfringens. ISRN Vet. Sci. 11:865702. https:// dx.doi.org/10.1155\%2F2013\%2F865702

Baums C.G., U. Schotte, G. Amtsberg and R. Goethe. 2004. Diagnostic multiplex PCR for toxin genotyping of Clostridium perfringens isolates. Vet. Microbiol. 100(12):11-16. https://doi.org/10.1016/s03781135(03)00126-3

Camacho, N., C. Espinoza, C. Rodriguez and E. Rodriguez. 2008. Isolates of Clostridium perfringens recovered from Costa Rican patients with antibiotic-associated diarrhoea are mostly enterotoxin-negative and susceptible to first-choice antimicrobials. J. Med. Microbiol. 57(3):343-347. https:// doi.org/10.1099/jmm.0.47505-0

Canard, B., T. Garnier, B. Saint-Joanis and S.T. Cole. 1989. Molecular genetic analysis of the nagH gene encoding a hyaluronidase of Clostridium perfringens. Mol. Gen. Genet. 243:215-224. https://doi.org/10.1007/ BF00280319

Cooper, K.K. and J.G. Songer. 2009. Necrotic enteritis in chickens, A paradigm of enteric infection by Clostridium perfringens type A. Anaerobe, 15(1-2):55-60.https:// doi.org/10.1016/j.anaerobe. 2009.01.006

Cooper, K.K., J.G. Songer, and F.A. Uzal. 2013. Diagnosing clostridial enteric disease in poultry. J. Vet. Diagn. Invest. 25(3): 314-
327. https:// doi.org/10.1177/1040638713483468

Coursodon, C.F., R.D. Glock, K.L. Moore, K.K. Cooper and J.G. Songer. 2012. TpeLproducing strains of Clostridium perfringens type A are highly virulent for broiler chicks. Anaerobe, 18(1):117-121. https://doi.org/10.1016/ j.anaerobe.2011.10.001

Craven, S.E., N.A. Cox, J.S. Bailey and D.E. Cosby. 2003. Incidence and tracking of Clostridium perfringens through an integrated broiler chicken operation. Avian Dis. 47(3):707-711.

https:// doi.org/10.1637/6010

Cruickshank, R., J.P. Duguid, B.R. Marmion and R.H.A. Swain. 1975. Medical Microbiology. (12 $2^{\text {th }}$ eds). Edinburgh: Churchill Livingstone. p. 812-825.

Dahiya, J.P., D.C. Wilkie, A.G. Van Kessel and M.D. Drew. 2006. Potential strategies for controlling necrotic enteritis in broiler chickens in post-antibiotic era. Anim. Feed Sci. Technol. 129(1-2): 60-88. https:// doi.org/10.1016/j.anifeedsci.2005.12.003

Datta, S., N.K. Rakha, G. Narang, D. Arora and N.K. Mahajan. 2014. Prevalence of $\alpha, \beta$ and Netb toxin producing strains of Clostridium perfringens in broiler chickens in Haryana. Haryana Vet. 53(1):39-42.

Duff A.F., C.N. Vuong, K.L. Searer, W.N. Briggs, K.M. Wilson, B.M. Hargis, L.R. Berghman and L.R. Bielke. 2019. Preliminary studies on development of a novel subunit vaccine targeting Clostridium perfringens mucolytic enzymes for the control of necrotic enteritis in broilers. Poult. Sci. 98:6319-6325. http:// dx.doi.org $/ 10.3382 / \mathrm{ps} / \mathrm{pez} 448$

Ebtehal, M.M. 2000. Studies on intestinal clostridial infections in broiler chicken. M.V.Sc. Thesis. Faculty of Veterinary Medicine, Assiut University, Egypt.

El-Rash, Amal, N. 2012. Studies on Clostridium perfringens in laying hens. M.V.SC. Thesis. Faculty of Veterinary Medicine, Cairo University, Egypt. 
El-Refaey, T.M. 1999. Bacteriological studies on Clostridium microorganisms in poultry. M.V. Sc. Thesis. Faculty of Veterinary Medicine, Cairo University, Egypt.

Elsharkawy, A.S., D. Talat, A.S. Elnaggar and M.S. Ibrahim. 2020. Detection of Clostridium perfringens and their virulence toxins in broiler chicken. Europ. J. Pharmaceut. Med. Res. 7(1):78-83.

EI-Jakee, J., S.A. Nagwa, A. Mona, S.M.A. Azza, H.H. Riham, N.M. Shawky and H.M. Shawky 2013. Characterization of Clostridium Perfringens isolated from poultry. Global Veterinaria 11(1): 88-94.

Eman A.K., M.D. Sohad, M.A. Bakry and A.S. Hakim. 2013. Molecular diversity of alpha toxin produced by Clostridium perfringens strains causing avian necrotic enteritis. World Appl. Sci. J. 21(1):15-20.

Engstrom, B.E., C. Fermer, A. Lindberg, E. Saarinen, V. Baverud and A. Gunnarsson. 2003.Molecular typing of isolates of Clostridium perfringens from healthy and diseased poultry. Vet. Microbiol. 94(3): 225235. https://doi.org/10.1016/s0378-1135 (03)00106-8

Fancher C.A., H.T. Thames, M.G. Colvin, L. Zhang, N. Nuthalapati, A. Kiess, T.T.N. Dinh and A.T. Sukumaran. 2021. Prevalence and molecular characteristics of Clostridium perfringens in "no antibiotics ever" broiler farms. Poult. Sci. 100(11): $101414 . \quad$ https://doi.org/10.1016/ j.psj.2021.101414

Finken, M.D. and Wages, D. 1997. Necrotic enteritis. In: Diseases of Poultry. (Y.M. Saif, B.W. Calnek, H.J. Barnes, C.W. Beard, L.R. McDougald, and Y.M. Said, 10th ed). Iowa State University Press. London. pp. 261-264.

Freedman, J.C., J.R. Theoret, J.A. Wisniewski, F.A. Uzal, J.I. Rood and B.A. McClanea. 2015. Clostridium perfringens type A-E toxin plasmids. Res. Microbiol. 166(4):264 -279 . $\quad$ https://dx.doi.org/10.1016\% 2Fj.resmic.2014.09.004

Gao, Z. and B.A. McClane. 2012. Use of Clos- tridium perfringens enterotoxin and the enterotoxin receptor-binding domain (CCPE) for cancer treatment: opportunities and challenges. J. Toxicol. 2012: 981626. https://doi.org/10.1155/2012/981626

Gholamiandekhordi, A.R., R. Ducatelle, M. Heyndrickx, F. Haesebrouck and F. Van Immerseel.2006. Molecular and phenotypical characterization of Clostridium perfringens isolates from poultry flocks with different disease status. Vet. Microbiol. 113(1-2):143-152. https:// doi.org/10.1016/j.vetmic.2005.10.023

Goossens, E., E. Dierick, R. Ducatelle and F. Van Immerseel. 2020. Spotlight on avian pathology: untangling contradictory disease descriptions of necrotic enteritis and necrohaemorrhagic enteritis in broilers. Avian Pathol. 49(5): 423-427. https:// doi.org/10.1080/03079457.2020.1747593

Gu, C., H.S. Lillehoj, Z. Sun, Y. Lee, H. Zhao, Z. Xianyu, X. Yan, Y. Wang, S. Lin, L. Liu and C. Li. 2019. Characterization of virulent netB $+/$ tpeL + Clostridium perfringens strains from necrotic enteritisaffected broiler chicken farms. Avian Dis. 63: 461-467. https://doi.org/10.1637/11973 -092018-reg. 1

Heikinheimo, A. and H. Korkeala. 2005. Multiplex PCR assay for toxinotyping Clostridium perfringens isolates obtained from Finnish broiler chickens. Lett. Appl. Microbiol. 40(6): 407-411. https:// doi.org/10.1111/j.1472-765x.2005.01702.x

Helal, S.S., N.M. Khalaf, A.A. El Menisy and M.A. Lebdah. 2019. Clostridium perfringens type A causing necrotic enteritis outbreaks among chickens in Egypt. Zagazig Vet. J. 47(4): 398-407. https:// dx.doi.org/10.21608/zvjz.2019.14139.1055

Henry, C.W., B.D. Murphy and R.A. Norton. 1995. Incidence of Clostridia [sic] perfringens on commercial broiler farms with a history of necrotic enteritis. Poult. Sci. 74(1): 51.

Hofacre, C.L., T. Beacorn, S. Collett and G. Mathis. 2003. Using competitive exclusion, 
mannanoligosaccharide and other intestinal products to control necrotic enteritis. J. Appl. Poult. Res. 12: 60-64.

Hussein, S.Z. and F.A. Mustfa. 1999. Necrotic enteritis in broiler chicken in Assiut governorate. Assiut Vet. Med. J. 41(82):239246.

Johansson, A., A. Aspan, M. Kaldhusdal and B.E. Engstrom. 2010. Genetic diversity and prevalence of netB in Clostridium perfringens isolated from a broiler flock affected by mild necrotic enteritis. Vet. Microbiol. 144(1-2):87-92. https:// doi.org/10.1016/j.vetmic.2009.12.017

Kalender, H. and H.B. Ertas. 2005. Isolation of Clostridium perfringens from chickens and detection of the alpha toxin gene by polymerase chain reaction (PCR). Turk. J. Vet. Anim. Sci. 29:847-851.

Kaneko, I., K. Miyamoto, K. Mimura, N. Yumine, H. Utsunomiya, S. Akimoto and B.A. McClane. 2011. Detection of enterotoxigenic Clostridium perfringens in meat samples by using molecular methods. Appl. Environ. Microbiol. 77(21):7526-7532. https://dx.doi.org/10.1128\%2FAEM.06216 $\underline{-11}$

Keyburn, A.L., X.X. Yan, T.L. Bannam, F. Van Immerseel, J.I. Rood and R.J. Moore. 2010. Association between avian necrotic enteritis and Clostridium perfringens strains expressing NetB toxin. Vet. Res. 41(2):2121. https://doi.org/10.1051/vetres/2009069

Kimy, B.Y., J.Y. Kim, C. Lee, J. Kwon, J. Kang, J.K. Rhee, M.S. Jeong, D. Young, Y.D. Nam and S.W. Roh. 2017. Complete genome sequence of Clostridium perfringens CBA7123 isolated from a faecal sample from Korea. Gut Pathog. 9: 32. https://doi.org/10.1186/s13099-017-0181-1

Kiu, R and L.J. Hall. 2018. An update on the human and animal enteric pathogen Clostridium perfringens. Emerg. Microbes Infect. 7: 141. https://dx.doi.org/10.1038\% 2Fs41426-018-0144-8

Kocher, A. 2003. Nutritional manipulation of necrotic enteritis outbreak in broilers. Re- cent Adv. Anim. Nutri. Australia, 14:111116.

Kumar, N.P., N.V. Kumar and A. Karthik. 2019. Molecular detection and characterization of Clostridium perfringens toxin genes causing necrotic enteritis in broiler chickens. Trop. Anim. Health Prod. 51(6):15591569. https://doi.org/10.1007/s11250-019$\underline{01847-9}$

Li, J., V. Adams, T.L. Bannam, K. Miyamoto, J.P. Garcia and A. Francisco. 2013. Toxin plasmids of Clostridium perfringens. Microbiol. Mol. Biol. Rev. 77(2):208-233. https:// doi.org/10.1128/mmbr.00062-12

Li, J., D. Paredes-Sabja, M.R. Sarker and B.A. McClane 2016. Clostridium perfringens sporulation and sporulation-associated toxin production. Microbiol. 4(3):1-27. https:// doi.org/10.1128/microbiolspec. tbs-00222015

Li, Z., W. Wang, D. Liu and Y. Guo, 2018. Effects of Lactobacillus acidophilus on the growth performance and intestinal health of broilers challenged with Clostridium perfringens. J. Anim. Sci. Biotechnol. 9: 25. https://doi.org/10.1186/s40104-018-0243-3

Long, J. and R. Truscott. 1976. Necrotic enteritis in broiler chickens. III. Reproduction of the disease. Can. J. Comp. Med. 40(1): 53-59.

Lovland, A. and M. Kaldhusdal 2001. Severely impaired production performance in broiler flocks with high incidence of Clostridium perfringens-associated hepatitis. Avian Pathol. 30(1):73-81. https:// doi.org/10.1080/03079450020023230

Lovland, A., M. Kaldhusdal, K. Redhead, E. Skjerve and A. Lillehaug. 2004. Maternal vaccination against subclinical necrotic enteritis in broilers. Avian Pathol. 33:83-92. https:// doi.org/10.1080/0379450310001636255

Lukinmaa, S., E. Takkunen and A. Siitonen 2002. Molecular epidemiology of Clostridium perfringens related to food-borne outbreaks of disease in Finland from 1984 to 1999. Appl. Environ. Microbiol. 68(8):3744 -3749 . 
2FAEM.68.8.3744-3749.2002

Manfreda, G., V. Bondioli, A. De Cesare and Franchini, A. 2006. Quantitative evaluation of Clostridium perfringens in Italian broilers. Poult. Sci. 62: 91-99.

Mateos, G.G., R. Lazaro and M.I. Gracia. 2002. The feasibility of using nutritional modifications to replace drugs in poultry feed. J. Appl. Poult. Res. 11(4): 437-452. https:// doi.org/10.1093/japr/ 11.4.437

Matsuda, A., M.S. Aung, M. Kawaguchiya, A. Sumi, M. Nakamura, Y. Horino, M. Ito, S.H. Nobumichi and N. Kobayashil. 2019. Prevalence and genetic diversity of toxin genes in clinical isolates of Clostridium perfringens: Coexistence of alpha-toxin variant and binary enterotoxin genes (bec/ cpile). Toxins (Basel). 11(6): 326. https:// doi.org/10.3390/toxins11060326

Mehtaz, S., P. Borah, R.K. Sharma and A. Chakraborty. 2013. Antibiogram of Clostridium perfringens isolated from animals and foods. Indian Vet. J. 90(1):54-60.

Miwa, N., T. Nishina, S. Kubo, M. Atsumi and H. Honda. 1998. Amount of enterotoxigenic Clostridium perfringens in meat detected by nest PCR. Int. J. Food Microbiol. 42(3):195-200. https://doi.org/10.1016/ s0168-1605(98)00082-8

Miyamoto, K., J. Li and B.A. Mc Clane. 2012. Enterotoxigenic Clostridium perfringens detection and identification. Microbes Environ. 27: 343-349. $\quad$ https:// dx.doi.org/10.1264\%2Fjsme2.ME12002

Moore, R.J. 2015. Necrotic enteritis in chickens an important disease caused by Clostridium perfringens. Microbiol. Aust. 36(3):118119.

Moore, R.J. 2016. Necrotic enteritis predisposing factors in broiler chickens. Avian Pathol. 45(3):275-281. https:// doi.org/10.1080/03079457.2016.1150587

Mwangi, S., J. Timmons, S. Fitz-coy and S. Parveen. 2019. Characterization of Clostridium perfringens recovered from broiler chicken affected by necrotic enteritis. Poult. Sci. 98(1):128-135. https:// doi.org/10.3382/ps/pey332

National Committee for Clinical Laboratory Standards (NCCLS) 2007. Performance Standards for Antimicrobial Susceptibility Testing; Fifteenth Informational Supplement According to CLSI. CLSI document M100-S15. Clinical and Laboratory Standards Institute, Wayne, PA.

Opengart, K. 2008. Necrotic enteritis. (Y. Saif, A.M. Fadly, J.R. Glisson, L.R. McDougald, L.K. Nolan and D.E. Swayne eds). Diseases of Poultry. 12th ed. Iowa, USA: Iowa State University Press. P. 872-879.

Osman, K.M., Y.A. Soliman, Z.M.S. Amin and M. Aly. 2012. Prevalence of Clostridium perfringens type $\mathrm{A}$ isolates in commercial broiler chickens and parent broiler breeder hens in Egypt. Rev. Sci. Tech. 31(3): 931941. https://doi.org/10.20506/rst.31.3.2169

Park, J.Y., S. Kim, J.Y. Oh, H.R. Kim, I. Jang and H.S. Lee. 2015. Characterization of Clostridium perfringens isolates obtained from 2010 to 2012 from chickens with necrotic enteritis in Korea. Poult. Sci., 94(6): 1158-1164. https://doi.org/10.3382/ps/ pev037

Parish, WE. 1961. Necrotic enteritis in fowl (Gallus gallus domesticus). Histopathology of the disease and isolation of strain of Clostridium welchii. J. Comp. Pathol. 71:377-393.

Prescott, J.F., V.R. Parreira, I. Mehdizadeh Gohari, D. Lepp and J. Gong 2016. The pathogenesis of necrotic enteritis in chickens: What we know and what we need to know: A review. Avian Pathol. 45: 288-294. https:// doi.org/10.1080/03079457.2016.1139688

Profeta, F., C.E. Di Francesco, A. Di Provvido, M. Scacchia, A. Alessiani, E. Di Giannatale, G.Marruchella, M. Orsini, T. Toscani and F. Marsilio. 2020. Prevalence of netBpositive Clostridium perfringens in Italian poultry flocks by environmental sampling. J. Vet. Diagn. Invest. 32: 252-258. https:// doi: $10.1177 / 1040638719885841$

Rasha, M. 2009. Studies on Clostridial microor- 
ganisms' infection in poultry and trials for vaccination. M. V. Sc. Thesis. Faculty of Veterinary Medicine, Minufiya University, Egypt.

Rood, J. I., A.L. Keyburn and R.J. Moore. 2016. NetB and necrotic enteritis: the hole movable story, Avian Pathol. 45 (3):295-301. https:// doi.org/10.1080/03079457.2016.1158781

Rood, J. I., V. Adams, J. Lacey, D. Lyras, B.A. McClane, S.B. Melville, R.J. Moore, M.R. Popoff, M.R. Sarker and J.G. Songer. 2018. Expansion of the Clostridium perfringens toxin-based typing scheme. Anaerobe 53:510. j.anaerobe.2018.04.011

Sasaki, J., M. Goryo, M. Makara, K. Nakamura and K. Okada. 2003. Necrotic hepatitis due to Clostridium perfringens infection in newly hatched broiler chicks. J. Vet. Med. Sci. 65(11):1249-1251. https:// doi.org/10.1292/jvms.65.1249

Skinner, J.T., S. Bauer, V. Young, G. Pauling and J. Wilson. 2010. An economic analysis of the impact of subclinical (mild) necrotic enteritis in broiler chickens. Avian Dis. 54 (4): 1237-1240. $\quad$ https:// doi.org/10.1637/9399-052110-reg.1

Thi, T.N., H. Vu-Khacorcid and T.N. Duc. 2021. Characterisation of Clostridium perfringens isolated from chickens in Vietnam. Vet. Med-Czech. 66: 431-439. https:// doi.org/10.17221/209/2020-VETMED

Timbermont, L., A. Lanckriet, A.R. Gholamiandehkordi, F. Pasmans, A. Martel, F. Haesebrouck, R. Ducatelle and F. Van Immerseel, 2009. Origin of Clostridium perfringens isolates determines the ability to induce necrotic enteritis in broilers. Comp. Immunol. Microbiol.Infect. Dis. 32 (6): 503-512. https://doi.org/10.1016/ j.cimid.2008.07.001

Timbermont, L., F. Haesebrouck, R. Ducatelle and F. VanImmerseel. 2011. Necrotic enteritis in broilers: an updated review on the pathogenesis. Avian Pathol. 40(4):341-347. https:// doi.org/10.1080/03079457.2011.590967

To, H., T. Suzuki, F. Kawahara, K. Uetsuka, S. Nagai, and T. Nunoya. 2017. Experimental induction of necrotic enteritis in chickens by a netB-positive Japanese isolate of Clostridium perfringens. J. Vet. Med. Sci. 79: 350358. https://doi.org/10.1292/jvms.16-0500

Tolooe, A., B. Shojadoost, S.M. Peighambar and Y. Tamaddon. 2011. Prevalence of netB gene among Clostridium perfringens isolates obtained from healthy and diseased chicks. J. Anim. Vet. Adv. 10:106-110.

Van Immerseel, F., J.I. Rood, R.J. Moore and R.W. Titball. 2008. Rethinking our understanding of the pathogenesis of necrotic enteritis in chickens. Trends Microbiol. 17 (1):32-36. https://doi.org/10.1016/ j.tim.2008.09.005

Wade, B., A.L. Keyburn, V. Haring, M. Ford, J.I. Rood and R.J. Moore. 2020. Two putative zinc metalloproteases contribute to the virulence of Clostridium perfringens strains that cause avian necrotic enteritis. J. Vet. Diagn. Invest. 32: 259-267. https:// doi.org/10.1177/1040638719898689

Wei, B., S.Y. Cha, J.F. Zhang, K. Shang, H.C. Park, J. Kang, K.J. Lee, M. Kang and H.K. Jang. 2020. Antimicrobial susceptibility and association with toxin determinants in Clostridium perfringens Isolates from Chickens. Microorganisms 8: 825. https:// doi.org/10.3390/ microorganisms 8111825

Willis, A.T. 1977. Characteristics of the pathogenic and related Clostridia. Anaerobic Bacteriology. Clinical and Laboratory Practice. ( $3^{\text {rd }}$ eds). London. Butterworth-Heinemann. P. 370

Wu, S.B., N. Rodgers and M. Choct. 2010. Optimized necrotic enteritis model producing clinical and subclinical infection of Clostridium perfringens in broiler chickens. Avian Dis. 54(3):1058-1065. https:// doi.org/10.1637/9338-032910-reg.1

Yang, W.Y., C.H. Chou and C. Wang. 2018. Characterization of toxin genes and quantitative analysis of netB in necrotic enteritis (NE)-producing and non-NE-producing 
Clostridium perfringens isolated from chickens. Anaerobe, 54: 115-120. https:// doi.org/10.1016/j.anaerobe.2018.08.010

Yoo, H.S., S.U. Lee, K.Y. Park and Y.H. Park. 1997. Molecular typing and epidemiological survey of prevalence of Clostridium perfringens types by multiplex PCR. J. Clin. Microbiol. 35(1):228-232. https:// doi.org/10.1128/jcm.35.1.228-232.1997

Zhang, B., L. Gan, M.S. Shahid, Z. Lv, H. Fan, D. Liu and Y. Guo. 2019. In vivo and in vitro protective effect of arginine against intestinal inflammatory response induced by Clostridium perfringens in broiler chickens. J. Anim. Sci. Biotechnol. 10: 73. https://doi.org/10.1186/s40104-019-0371-4 